\title{
A INSERÇÃO DA MULHER COMO PROFISSIONAL CONTÁBIL NOS ESCRITÓRIOS DE CONTABILIDADE DE TANGARÁ DA SERRA - MT
}

\author{
Ingrid Prudêncio Siqueira ${ }^{1}$ \\ Laércio Juarez Melz ${ }^{2}$ \\ Josiane Silva Costa dos Santos ${ }^{3}$ \\ Ariel Lopes Torres ${ }^{4}$
}

\section{RESUMO}

O mercado de trabalho sempre pareceu algo distante para as mulheres, porém com as diversas lutar e revoluções aos poucos ganharam espaço na sociedade. Ainda assim, a profissão contábil, sempre foi muito visada tipicamente masculina. Após ganhar confiança como profissional nos mais diversos setores de desenvolvimento econômico, as mulheres têm se mostrado competentes suficientemente para ocupar cargos de destaque nas organizações. Perante esta realidade busca-se avaliar, pelo meio de entrevistas, a inserção da mulher como profissional contábil nos escritórios de contabilidade da cidade de Tangará da Serra- MT. A pesquisa exibe relevância para a comunidade, por se tratar de um estudo original que proporciona informações importantes para funcionários e proprietários dos escritórios.

Palavras-chave: Contabilidade; Mulher; Valorização.

\section{INTRODUÇÃO}

A sociedade vem quebrando tabus com relação à mulher, cedendo cada vez mais espaços para a atuação e valorização feminina, apesar do predomínio de uma sociedade patriarcal. A crescente participação da mulher no mercado de trabalho também é observada em sua atuação na Ciência Contábil.

As mulheres tem se preparado continuamente para atuar nos mais diversos setores e níveis oferecidos pelo mercado, buscando a realização pessoal e contribuição para melhoria do bem-estar da sociedade, agregando a rotina das empresas habilidades próprias e importantes, como a motivação, capacidade de trabalhar em grupo, administrar conflitos e lidar com recursos escassos. e mesmo assim, elas ainda se deparam com as barreiras culturais do preconceito e da discriminação estabelecidas pelos homens (COSTA,2010)

As mais diversas organizações vêm reconhecendo o papel fundamental que a mulher tem desempenhado, de maneira eficiente e eficaz. Segundo Costa (2010) A inserção feminina no mercado de trabalho tem se tornado relevantemente competitiva em relação ao

\footnotetext{
${ }^{1}$ Acadêmico do curso de Ciências Contábeis da UNEMAT - Campus de Tangará da Serra, ps.ingrid@ msn.com

2 Mestre em Engenharia de Produção (UFSCar), Professor do Departamento de Ciências da UNEMAT Campus de Tangará da Serra, laercio@unemat.br

${ }^{3}$ Contadora, Professora do curso de Ciências Contábeis da UNEMAT - Campus de Tangará da Serra.

${ }^{4}$ Mestre em Administração (UNEX), Professor do curso de Ciências Contábeis da UNEMAT - Campus de Tangará da Serra.
} 
A inserção da mulher como profissional contábil nos escritórios de contabilidade de Tangará da Serra-

Ingrid Prudêncio Siqueira, Laércio Juarez Melz, Josiane Silva Costa dos Santos, Ariel Lopes Torres

universo masculino, devido a presença da mulher contribuir para o sucesso dos negócios com um toque exclusivo e especial às organizações. Assim, as organizações se rendem à força da mão de obra feminina, investindo em programas de desenvolvimento, valorização e na igualdade entre gêneros.

Diante dessa conjuntura a pesquisa teve como objetivo analisar inserção e a evolução participativa das mulheres nos escritórios de contabilidade de Tangará da Serra - Mato Grosso, bem como verificar os cargos ocupados, a compatibilidade salarial com um homem desempenhando a mesma função, assim como as dificuldades enfrentadas para ocupação de cargos/funções por serem do sexo feminino.

\section{REFERENCIAL TEÓRICO}

\subsection{História do trabalho}

Trabalho é toda e qualquer atividade física ou mental visando um objetivo, ocupação ou mesmo transformação. De forma ampla, trabalho é atividade que transforma a natureza a partir de certa matéria. Reis (2006) conceitua esforços físicos ou mentais, como desprendimento da energia física/mental, para desenvolver um bem ou atividade. No sentido técnico, o trabalho desempenha produção, porém se o trabalho for analisado economicamente, exerce funcionalidade lucrativa e geração de emprego.

Luisa Sanverino, apud Caupers (1985), "a noção de trabalho supõem uma actividade econômica, uma actividade orientada para a produção ou troca de bens (econômicos) ou serviços. A noção de trabalhador abrangeria também o produtor, vindo a integrar aquilo a que se chama operador econômico"

Para Marx (1895)

Antes de tudo, o trabalho é um processo entre o homem e a natureza, um processo em que o homem, por sua própria ação, pode mediar, regular e controlar seu metabolismo com a natureza. (...) Uma aranha executa operações semelhantes à do tecelão, e a abelha envergonha mais de um arquiteto humano com a construção dos favos de suas colméias. Mas o que distingue, de antemão, o pior arquiteto da melhor abelha é que ele construiu o favo em sua cabeça antes de construí-lo em cera. No fim do processo de trabalho, obtém-se um resultado que, já no início deste, existiu idealmente na imaginação do trabalhador

Na visão de Konder (1981)

É no trabalho que o homem se produz a si mesmo. O trabalho é o núcleo a partir do qual podem ser compreendidas as formas complicadas da atividade criadora do sujeito humano. Foi com o trabalho que o ser humano 'desgrudou-se' um pouco da natureza e pôde, pela primeira vez, contrapor-se como sujeito ao mundo dos objetos naturais. Se não fosse o trabalho, não existiria a relação sujeito-objeto 
A inserção da mulher como profissional contábil nos escritórios de contabilidade de Tangará da SerraMT

Ingrid Prudêncio Siqueira, Laércio Juarez Melz, Josiane Silva Costa dos Santos, Ariel Lopes Torres

O trabalho tem papel importante para a sociedade, atravéz dele, o homem permitiu conhecer a sí e ao próximo, além de permitir desenvolver a arte de trasformação do ser e da matéria. ARANHA (1996) aborta o trabalho como ação transformadora a respeito do homem e a natureza, sendo capaz de diversifiar pensamento, ações, sentido e sentimentos, até o término de uma atividade, independente de qual seja a sua execução. A relação da cultura do homem com o trabalho e a natureza sofre modificações com os regimes políticos em diferentes momentos da história, embasado nas adaptações em que deveriam sofrer para garantir sobrevivência.

A primeira forma de trabalho foi a escravidão; homem não obtinha direito e era considerado propriedade, mercadoria, sendo avaliado uma "coisa". Moreira, Gonçalves e Costa (2004), abordam o motivo pelo qual se considerava o homem uma "coisa": faltava-lhe racionalidade. Assim, não tinham direito a liberdade ou integridade física. A liberdade era conquistada, com gratidão de seus senhores devido a algum serviço prestado, ou através da morte. Apesar de libertos, muitos se alugavam a terceiros, porém, recebiam salários.

Durante o regime escravista, continua a divisão do trabalho, sendo que a divisão dignificava a especialização e o aperfeiçoamento dos instrumentos e maior conhecimento técnico. Após os cereais, na agricultura nascem as especialidades de hortigranjeiros, frutícolas, etc.; é aperfeiçoado o arado primitivo que agora ganha rodas e criam-se novas ferramentas para usos mais específicos; a força dos animais é usada em maior porcentagem. O trabalho de grande número de escravos permite a construção de obras maiores, como canais, represas, caminhos, navios, prédios, etc. E as pessoas da sociedade livre que já não precisavam desenvolver trabalhos físicos ficam com tempo para se dedicar às artes e às ciências. (CARTES, 2006)

Cartes, (2006) conclui que havendo tempo para estudos das artes e da ciência, há abundancia de mão de obra, resultando em redução salarial dos escravos e desinteresse dos senhores no aperfeiçoamento das técnicas de produção.

Outra forma de escravidão surgiu por volta do século XI, a Servidão, compreendendo o sistema feudal. Nesse período o homem passa a ser reconhecido como uma pessoa, e começa a ter direitos, mesmo que extremamente limitados. Entende Reis (2006) que os trabalhador se localiza no primeiro degrau da escada da liberdade, considera ainda que ele subirá lentamente, com sofrimentos e recuos. Aos servos que não eram livres, e prestavam serviço aos feudos, os senhores feudais davam-lhes proteção em troca de parte da produção, gerando uma relação de fidelidade entre servos e senhores (BACELLAR, 2003). 
A inserção da mulher como profissional contábil nos escritórios de contabilidade de Tangará da SerraMT

Ingrid Prudêncio Siqueira, Laércio Juarez Melz, Josiane Silva Costa dos Santos, Ariel Lopes Torres

O sistema feudal foi substituído por volta do século XVI por um novo sistema econômico e social, as Corporações de Ofício. Marcante (2005) afirma que, as Corporações eram organizações artesanais, com mestres e subordinados, e devido as especializações, acarretando em novas forma de se produzir, assim como o trabalho com pagamento salarial.

As corporações apresentavam estatutos ou regulamentos, que controlava e organizava as condições de trabalho, tais como a quantidade de oficiais e salários, horário de trabalho, inclusive descanso e dias festivos, entre outros (GARCIA, 2001)

As corporações de ofício se extinguem em 1791, com a Lei Chapelier, originária da Revolução Francesa (1789) e seus ideais, Liberdade, Igualdade e Fraternidade. No Brasil, as corporações de ofício foram abolidas, no Art 179, inc XXV da Constituição brasileira de 1824:

Art. 179. A inviolabilidade dos Direitos Civis, e Políticos dos Cidadãos Brasileiro, que tem por base a liberdade, a segurança individual, e a propriedade, é garantida pela Constituição do Império, pela maneira seguinte:

XXV. Ficam abolidas as Corporações de Ofícios, seus Juízes, Escrivães, e Mestres."

Além da Revolução Francesa, outro movimento revolucionou as formas de trabalho, a Revolução Industrial. Iniciou na Inglaterra, em meados do século XVIII, se expandindo para o mundo no século XIX, trouxe consigo tecnologia, e união das classes trabalhistas. A Revolução Industrial tem como características, o aumento da produção, feito pelo qual, os trabalhadores se tornam responsável por uma parte do produto, diferentemente de antes, com a manufatura, a produção era responsabilidade de uma única pessoa (REIS, 2006).

A evolução humana e histórica, tal como a Revolução Industrial (meados do Séc. XVIII) acarretou em mudanças, culturais e tecnológicas, gerando força no setor produtivo, econômico e social. A Máquina possui função importante, porém o homem é quem desempenha e alimenta o processo, definindo as atividades e controlando a produção, "porque é o homem quem deve dar sentido ao trabalho e não o oposto.” (ARAÚJO, 2008).

Reis (2006) Conclui afirmando que, a revolução industrial, procedente do uso das máquinas e aperfeiçoamento de técnicas, conquistas novos mercados e por consequência, acumula capitais nas mãos dos proprietários das empresas, surgindo então o regime capitalista, o qual provém até a atualidade.

\subsection{A mulher na história}

A mulher, sempre buscou e lutou por seus direitos, por um espaço perante a sociedade. Busca por cargos, por reconhecimento, méritos. Ao longo da história, com muita 
A inserção da mulher como profissional contábil nos escritórios de contabilidade de Tangará da SerraMT

Ingrid Prudêncio Siqueira, Laércio Juarez Melz, Josiane Silva Costa dos Santos, Ariel Lopes Torres

luta, a sociedade sofre mutações, revoluções, e inserções de novos povos, culturas, e principalmente, da mulher, como ser, como mulher (HAHNER, 2003)

Para Hahner (2003), em meados do século XIX, o Brasil mostrava-se atraente para os europeus, chamava a atenção pela diversidade social, belezas naturais, mas pouco se notava mulher, sendo ela escrava, senhora da fazenda, ou mesmo a Imperatriz, e quando percebida a sua presença, sua imagem era sempre de mulher submissa, com marido autoritário, gerava inúmeras crianças e abusava dos escravos.

Hahner (2003) diz ainda que as escravas, às vezes, podiam conquistar certa autonomia nas cidades,. Muitas delas, iam exerciam o trabalho como lavadeiras, domésticas, cozinheiras,ou mesmo amas de leite. As escravas estavam sujeitas à violência sexual, e podiam a qualquer momento ser separada de seu filhos. Diferentemente, as mulheres livres, muitas vezes dirigiam moradias de portes, criados, e escravos, além de supervisionarem a produção de alimentos, utensílios e roupas. Apesar de livres, boa partes das mulheres permaneciam recolhidas em casa. Somente a viuvez, liberava-as de algumas restrições.

A lei vetava às mulheres casadas, o direito de se relacionar no comércio, alienar bens imóveis, por venda ou doação, além de, conduzir a propriedade, sem o concordância de seus maridos. (ARARIPE, 1885).

Os trabalhos tradicionalmente ocupados por mulheres eram impregnados por um duplo problema: algumas vezes a empurravam para a reclusão da vida privada como no caso das costureiras, bordadeiras, roceiras, que, apesar do não comprometimento moral de suas atividades, não lhes permitiam romper com o estigma de inferioridade -, outras eram ocupações ilícitas: da mulher pública. Assim adjetivado, o trabalho feminino fora do seio doméstico era apresentado com uma forte carga de amoralidade, como as prostitutas e as donas de bordéis. (NASCIMENTO e OLIVEIRA, 2006)

Para Hahner (2003), as prostitutas eram vistas como mulheres gananciosas e preguiçosas, com a sexualidade acentuada, elo transportador de doenças venéreas, apesar de serem consideradas um "mal necessário", sendo esta, tradicional. Outra atividade tradicionalmente feminina era o serviço doméstico, fornecendo mais emprego para as mulheres de baixa classe, do que as próprias fábricas, oficinas ou qualquer outro âmbito da economia. A maioria dessas mulheres ainda vivia à guarda de seus patrões, considerando que, os mesmo regulamentavam as condições de trabalho.

Embora a os operários das fábricas e indústrias serem minoria entre as classe mais baixa,homem mulheres e crianças, recebiam baixo salário em troca de muitas horas trabalhadas. Além de sofrerem humilhações, insultos, e maus tratos, as mulheres sofriam abuso sexual de seus supervisores (HAHNER, 2003) 
A inserção da mulher como profissional contábil nos escritórios de contabilidade de Tangará da SerraMT

Ingrid Prudêncio Siqueira, Laércio Juarez Melz, Josiane Silva Costa dos Santos, Ariel Lopes Torres

Para Probst (2007), somente no século XIX, com a consolidação do capitalismo, diversas mudanças ocorreram na organização do trabalho feminino. $\mathrm{O}$ desenvolvimento da tecnologia refletiu diretamente na mão de obra, sendo ela, boa parte transferida para as fábricas. A partir de então, criaram-se algumas leis para o beneficiamento das mulheres.

Desde então, algumas leis passaram a beneficiar as mulheres. Ficou estabelecido na Constituição de 32 que "sem distinção de sexo, a todo trabalho de igual valor correspondente salário igual; veda-se o trabalho feminino das 22 horas às 5 da manhã; é proibido o trabalho da mulher grávida durante o período de quatro semanas antes do parto e quatro semanas depois; é proibido despedir mulher grávida pelo simples fato da gravidez. (PROBST, 2011)

Probst (2011), conclui dizendo que, apesar das mudanças propostas e previstas em lei, algumas explorações permaneceram ainda durante muito tempo. A diferença na carga horária de trabalho e salariais eram comuns, e a justificativa para tal, era de que, a mulher era sustentada pelo homem, e por isso não havia necessidade de um salário equivalente ou superior ao dele.

Embora, a Constituição Federal Brasileira,prever igualdade de todos perante a lei, desde 1934, esses direitos passam a ser reconhecido a partir de 1988:

\footnotetext{
art. $5^{\circ}$ : Todos são iguais perante a lei, sem distinção de qualquer natureza, garantindo-se aos brasileiros e aos estrangeiros residentes no País a inviolabilidade do direito à vida, à liberdade, à igualdade, à segurança e à propriedade, nos termos seguintes: I - Homens e mulheres são iguais e direitos e obrigações, nos termos desta Constituição;

art. 183 - Aquele que possuir como sua área urbana de até duzentos e cinquenta metros quadrados, por cinco anos, ininterruptamente e sem oposição, utilizando-a para sua moradia ou de sua família, adquirir-lhe-á o domínio, desde que não seja proprietário de outro imóvel urbano ou rural.

$\S 1^{\circ}$ - O título de domínio e a concessão de uso serão conferidos ao homem ou à mulher, ou a ambos, independentemente do estado civil.

art. 189 - Os beneficiários da distribuição de imóveis rurais pela reforma agrária receberão títulos de domínio ou de concessão de uso, inegociáveis pelo prazo de dez anos.

Parágrafo único. O título de domínio e a concessão de uso serão conferidos ao homem ou à mulher, ou a ambos, independentemente do estado civil, nos termos $\mathrm{e}$ condições previstos em lei.

art. 201, V - pensão por morte de segurado, homem ou mulher, ao cônjuge ou companheiro e dependentes, obedecido o disposto no $\S 5^{\circ}$ e no art. 202.

art. 226, $\S 5^{\circ}$ - Os direitos e deveres referentes à sociedade conjugal são exercidos igualmente pelo homem e pela mulher

art. $7^{\circ}$, XVIII - licença à gestante, sem prejuízo do emprego e do salário, com a duração de cento e vinte dias;
}

\subsection{A contabilidade}

Para Marion (2004) a Contabilidade é o instrumento que possibilita o maior número de informações úteis para a tomada de decisões, dentro ou fora das organizações. Franco (2006) relata a contabilidade como função de registrar, classificar, demonstrar, auditar e analisar, a movimentação do patrimônio das entidades. Marion (2004) afirma que, uma 
empresa em uma boa Contabilidade, é o mesmo que um barco em alto-mar, porém, sem bússola.

A contabilidade possui diversos usuários, pessoas que se interessam pela saúde da empresa ou mesmo que buscam a contabilidade como alternativa. Gerentes e administradores não são os únicos interessados e utilizadores da contabilidade. Os investidores (sócios os acionistas) aplicam dinheiro nas empresas no intuito de obter lucro, para isso, utilizam relatórios contábeis analisando a rentabilidade de tal investimento. Os fornecedores a prazo fazem uso, verificando as condições da empresa para pagamento de dívidas. Os bancos avaliam informações contábeis a modo que possibilitem ou não empréstimo de dinheiro. $\mathrm{O}$ governo, os sindicatos, empregados, concorrentes... De maneira geral, a informações contábeis é de interesse de todos (MARION, 2004)

A Contabilidade pode ser realizada tanto para Pessoa Física quanto para Pessoa Jurídica. De forma Jurídica, toda pessoa capaz de direito e obrigações.

A pessoa física, afirma Poloni (2012), é todo o indivíduo, pessoa natural (sem exceção). Conforme Diniz (2007), pessoa jurídica pode ser definido como integração de pessoas naturais ou de patrimônios, reconhecida pela ordem jurídica como sujeito de direitos e obrigações, que visa alcançar certos objetivos.

Portanto, qualquer pessoa, sendo ela Física (mesmo que incomum) ou Jurídica, que tenha precisão da contabilidade ( a Contabilidade seja mandita para esta pessoa), é chamada de entidade contábil (MARION, 2004).

Os responsáveis pela contabilidade das entidades, elaborar e analisar os balanços patrimoniais das mesma, são os Contabilistas. Estes podem ser técnicos em contabilidade, com apenas cursos técnicos em contabilidade, ou Contadores, quando término do curso superior e Bacharel em Ciências Contábeis. Porém, o Contador, está habilitado a exercer atividades não cabíveis ao técnico, tais como: Auditoria, Perícia Contábeis e Professor de Contabilidade. (MARION, 2004)

Para Marion (2004), A auditoria é o exame e verificação da exatidão dos procedimentos contábeis. Na visão de Attie (2001), Auditoria é uma especialização contábil, voltada a testar a eficiência e eficácia do controle patrimonial. Lisboa (2010), a Auditoria avalia e presta auxílio a Administração e desenvolve adequadamente suas atribuições, o que proporciona análises e recomendações diante das atividades examinadas.

Marion (2004), a Perícia Contábil é a investigação contábil da empresa, solicitada pela justiça. Juliano (2009) é quando o perito é convocado pela Justiça para apresentar laudos 
A inserção da mulher como profissional contábil nos escritórios de contabilidade de Tangará da SerraMT

Ingrid Prudêncio Siqueira, Laércio Juarez Melz, Josiane Silva Costa dos Santos, Ariel Lopes Torres

técnicos em processos judiciais, nos quais podem constar envolvimento de pessoas físicas, jurídicas e/ou mesmo órgãos públicos. Professor de Contabilidade, na visão de Marion (2004) no curso superior de contabilidade, exige-se especialização.

\subsection{A mulher no mercado de trabalho}

A população feminina vem aumentando significativamente, a mulher vive em média 8 (oito) anos a mais que o homem. Conforme o Instituto Brasileiro de Geografia e Estatística (IBGE, 2007), a queda da taxa de fecundidade, o aumento da expectativa de vida, são fatores relativamente importantes. A redução da fecundidade ocorreu intensivamente em meios aos anos de 70 e 80 . A década de 90 já começou com uma taxa baixa de fecundidade: $2,6 \%$ que cai para 2,3\% no fim da década, (PROBST, 2011)

Recordo-me de uma palestra de Tom Peters, proferida em 2000. Perguntaram-lhe: "Se o senhor tivesse uma grande empresa e fosse se Aposentar, o que faria?" Sem tibubear, ele respondeu que contrataria para o mais alto cargo executivo uma mulher dinâmica e inteligente, recrutada em uma boa escola. Em seguida, selecionaria 100 jovens talentosos, já familiarizados com os instrumentos e ambientes da era digital, e os colocaria sob as ordens dessa líder. Segundo ele, essa seria a fórmula ideal para garantir a longevidade da empresa, com elevados padrões de qualidade e competitividade. Exageros à parte, concordo que a proposta de Peters aponta para modelos corretos de reivindicação das organizações. As mulheres, sem dúvida, têm se adaptado mais rapidamente a essa realidade competitiva dos novos tempos (JULIO, 2002, p. 135).

Ainda que seja mais difícil assumir cargos de maior poder, prestígio e reputação, as mulheres expandiram seu campo de atuação profissional e tem investido no aumento do nível de instrução, buscando alcançar, as maiores e melhores oportunidades no mercado de trabalho (ROCHA-COUTINHO, 2003)

A mulher tem se mostrado cada vez mais competente e eficiente, no trabalho em que realiza. Vêm ganhando espaço diversos segmentos, e na contabilidade não é diferente. Segundo dados do Conselho Federal de Contabilidade (CFC, 2012), Mais de 190 mil mulheres contribuem para o desenvolvimento da profissão, o que representa $41 \%$ do total de Profissionais Contábeis. Deste, são 128 mil contadoras e 70 mil técnicas em Contabilidade, perfazendo um total de 198.802 profissionais que representam a classe em todo o País. Em alguns estados brasileiro, a participação da mulher na profissão, chega a 50\% , diz o Presidente do CFC, Juarez Domingues Carneiro. "O mercado absorveu muito bem a mulher tanto por sua competência, como pelo meticuloso senso de organização e de disciplina", afirma Carneiro.

De acordo com dados divulgados pelo CFC (2012), o Mato Grosso representa 2,1089 dos profissionais contábeis no Brasil, um total de 10.222 contadores e técnicos em 
A inserção da mulher como profissional contábil nos escritórios de contabilidade de Tangará da Serra-

Ingrid Prudêncio Siqueira, Laércio Juarez Melz, Josiane Silva Costa dos Santos, Ariel Lopes Torres

contabilidade. Deste número, 46,7130 ou seja 4.775 são mulheres. O mercado de trabalho ficou ainda mais competitivo, com a presença feminina.

Além do mercado competitivo, tornou-se qualitativo, principalmente para a mulher "Essa é a grande virada e a mulher contabilista está abraçando este desafio com toda a garra que lhe é peculiar" define Maria Clara Cavalcante Bugarim, vice-presidente de Desenvolvimento Profissional e Institucional do CFC. Para Bugarim, o maior desafio da mulher, é o aprendizado contínuo e a busca pela qualificação profissional, que norteará o indivíduo na profissão, independentemente do gênero.

Com reconhecimento e incentivo a mulher na contabilidade, desde 1991, o CFC realiza o Encontro Nacional da Mulher Contabilista, com palestras e discussões sobre a realidade da mulher profissional de contabilidade. Segundo Carneiro, o encontro possibilita troca de experiências, atualização profissional e capacitação, dentro de uma programação trabalhada com muito profissionalismo.

\section{METODOLOGIA}

A ferramenta utilizada, quanto ao procedimento de coleta o de dados, se deu por meio de questionários. Assim como por meio de pesquisa bibliográficas com base em livros, artigos científicos e reportagens relacionados a participação feminina no mercado de trabalho, especificamente para o ramo contábil.

O tema abordado possui características qualitativas e exploratórias, que segundo IBOPE (2004) é através desse tipo de pesquisa, é possível fazer surgir feitos particulares e novas motivações implícitas, de forma espontânea. Assim como, também tem características quantitativas devido a utilização de cálculos para quantificar os dados coletados. De acordo com Oliveira (1999) a abordagem quantitativa acarreta em resultados precisos, evitando distorção quanto à interpretação e análise.

A coleta de dados foi feita com público específico, exclusivamente para mulheres atuantes como profissionais contábeis, de toda faixa etária; sendo analisados 10 (dez) Escritórios de contabilidade de Tangará da Serra, totalizando 28 opiniões. Dessa maneira, foi possível caracterizá-las e observar o índice de participação e cargos exercido. 
A inserção da mulher como profissional contábil nos escritórios de contabilidade de Tangará da SerraMT

Ingrid Prudêncio Siqueira, Laércio Juarez Melz, Josiane Silva Costa dos Santos, Ariel Lopes Torres

\section{RESULTADOS}

Através dos questionários aplicados nos escritórios de contabilidade, foi possível verificar a faixa etária das mulheres em cada organização. Dos 28 questionários analisados, cerca de 53,57\% das entrevistadas, possuem idade entre 21 à 30 anos, possibilitando análise de que estas iniciam-se, em média, a partir dos 20 anos de idade, no mercado de trabalho contábil.

Ao olharmos o contexto histórico da mulher na sociedade, notamos a constante guerra dos sexos em busca de igualdade e valorização da mulher. Em diversos setores, a presença exclusivamente masculina submergiu a força de movimentos feministas, que se expandiram rapidamente, tais como o direito a voto, ao ensino, grandes cargos em organizações, entre outros; além de permitir o acesso precocemente a essas oportunidades. Tais dados são possíveis verificar na tabela abaixo.

Tabela 01. Idade - Escritórios Contábeis de Tangará da Serra/2012

\begin{tabular}{l|r}
\hline IDADE & \% \\
\hline 21 a 30 anos & $53,57 \%$ \\
\hline 31 a 40 anos & $17,86 \%$ \\
\hline Até 20 anos & $28,57 \%$ \\
\hline Total Geral & $\mathbf{1 0 0 , 0 0 \%}$ \\
\hline
\end{tabular}

Fonte: Dados coletados pelo autor.

Após anos de lutas às oportunidades, ainda é necessário constantes aperfeiçoamentos para concorrer com os homens. Estudos, bacharelados, cursos técnicos, graduação são requisitos importantes no mercado de trabalho. Independente da faixa etária, as mulheres entrevistadas estão em busca de conhecimento e aprimoramentos.

Analisando aos dados coletados com as 28 mulheres entrevistadas, o correspondente a $60,71 \%$ cursam nível superior. Representando as profissionais formadas obteve-se o total de $39,29 \%$ onde destas $10,71 \%$ possuem especialização e o mesmo percentual é corresponde às que estão cursando pós-graduação ou MBA. Essas informações podem ser melhor visualizadas na tabela 02 e 03 .

Tabela 02. Grau de Instrução- Escritórios Contábeis de Tangará da Serra/2012

\begin{tabular}{l|l|r|r}
\hline Graduação & Cursando & Sim & Total Geral \\
\hline 1 ano e 9 meses & $0,00 \%$ & $7,14 \%$ & $7,14 \%$ \\
\hline 16 anos & $0,00 \%$ & $3,57 \%$ & $3,57 \%$ \\
\hline 2 anos e 1 meses & $0,00 \%$ & $3,57 \%$ & $3,57 \%$ \\
\hline 2 anos e 7 meses & $0,00 \%$ & $3,57 \%$ & $3,57 \%$ \\
\hline
\end{tabular}


A inserção da mulher como profissional contábil nos escritórios de contabilidade de Tangará da SerraMT

Ingrid Prudêncio Siqueira, Laércio Juarez Melz, Josiane Silva Costa dos Santos, Ariel Lopes Torres

\begin{tabular}{l|l|r|r}
\hline 2 anos e 9 meses & $0,00 \%$ & $3,57 \%$ & $3,57 \%$ \\
\hline 3 anos e 8 meses & $3,57 \%$ & $3,57 \%$ & $57,00 \%$ \\
\hline 5 anos & $0,00 \%$ & $3,57 \%$ & $3,57 \%$ \\
\hline 7 anos & $0,00 \%$ & $3,57 \%$ & $3,57 \%$ \\
\hline Não responderam & $57,14 \%$ & $7,14 \%$ & $64,29 \%$ \\
\hline Total Geral & $\mathbf{6 0 , 7 1 \%}$ & $\mathbf{3 9 , 2 9 \%}$ & $\mathbf{1 0 0 , 0 0 \%}$ \\
\hline
\end{tabular}

Fonte: Dados coletados pelo autor.

Tabela 03. Grau de Instrução (Especialização) - Escritórios Contábeis de Tangará da Serra/2012

\begin{tabular}{l|r}
\hline Especialização & \% \\
\hline Cursando & $10,71 \%$ \\
\hline Não & $75,00 \%$ \\
\hline Sim & $10,71 \%$ \\
\hline Não responderam & $3,57 \%$ \\
\hline Total Geral & $\mathbf{1 0 0 , 0 0 \%}$ \\
\hline
\end{tabular}

Fonte: Dados coletados pelo autor.

A participação da feminina no mercado de trabalho ganhou aumento significativo no decorrer da história, porém determinados funções e cargos ainda eram de uso e acesso exclusivo dos homens. Aos poucos esse quadro de funcionalidades obteve alterações, permitindo a presença feminina até mesmo em Graus elevados de supervisão.

Ainda que não seja de maneira expressiva nos escritórios de Tangará da Serra, quase $11 \%$ das mulheres entrevistadas exercem cargos de supervisão, sendo encarregadas de algum departamento contábil. Para assumirem tal funcionalidade, estas possuem tempo mínimo de 04 (quatro) anos como tempo de atuação.

Tabela 04. Tempo de atuação versus Cargo - Escritórios Contábeis de Tangará da Serra/2012

\begin{tabular}{l|r|r|r}
\hline Tempo de atuação / Cargo & Auxiliar & Encarregada & Total Geral \\
\hline 1 ano e 2 meses & $3,57 \%$ & $0,00 \%$ & $3,57 \%$ \\
\hline 1 ano e 3 meses & $3,57 \%$ & $0,00 \%$ & $3,57 \%$ \\
\hline 1 ano e 6 meses & $17,86 \%$ & $0,00 \%$ & $17,86 \%$ \\
\hline 1 ano e 8 meses & $3,57 \%$ & $0,00 \%$ & $3,57 \%$ \\
\hline 1 semana & $3,57 \%$ & $0,00 \%$ & $3,57 \%$ \\
\hline 10 anos & $3,57 \%$ & $0,00 \%$ & $3,57 \%$ \\
\hline 15 anos & $0,00 \%$ & $3,57 \%$ & $3,57 \%$ \\
\hline 18 anos e 4 meses & $3,57 \%$ & $0,00 \%$ & $3,57 \%$ \\
\hline 2 anos e 1 mês & $7,14 \%$ & $0,00 \%$ & $7,14 \%$ \\
\hline 2 anos e 6 meses & $3,57 \%$ & $0,00 \%$ & $3,57 \%$ \\
\hline 2 anos e 8 meses & $7,14 \%$ & $0,00 \%$ & $7,14 \%$ \\
\hline 4 anos e 8 meses & $0,00 \%$ & $3,57 \%$ & $3,57 \%$ \\
\hline 4 meses & $7,14 \%$ & $0,00 \%$ & $7,14 \%$ \\
\hline 5 anos e 2 meses & $3,57 \%$ & $0,00 \%$ & $3,57 \%$ \\
\hline 5 anos e 3 meses & $0,00 \%$ & $3,57 \%$ & $3,57 \%$ \\
\hline
\end{tabular}


A inserção da mulher como profissional contábil nos escritórios de contabilidade de Tangará da SerraMT

Ingrid Prudêncio Siqueira, Laércio Juarez Melz, Josiane Silva Costa dos Santos, Ariel Lopes Torres

\begin{tabular}{l|r|r|r}
\hline 6 meses & $3,57 \%$ & $0,00 \%$ & $3,57 \%$ \\
\hline 7 meses & $3,57 \%$ & $0,00 \%$ & $3,57 \%$ \\
\hline Não responderam & $14,29 \%$ & $0,00 \%$ & $14,29 \%$ \\
\hline Total Geral & $\mathbf{8 9 , 2 9 \%}$ & $\mathbf{1 0 , 7 1 \%}$ & $\mathbf{1 0 0 , 0 0 \%}$ \\
\hline
\end{tabular}

Fonte: Dados coletados pelo autor.

Não menos importante, as auxiliares representam uma margem de quase $90 \%$ das entrevistadas. Normalmente fazem parte das auxiliares as mulheres não formadas, porém que estejam cursando nível técnico ou superior. Entretanto, não há nada que empeça uma bacharel em ser auxiliar de determinado departamento.

De maneira geral, é possível observar o quanto a mulher tem se desenvolvido em seu trabalho, e se mantido estável. A média geral por tempo de função, seja esta auxiliar ou encarregada de setor, e superior a mínima de 2 (dois anos).

Tabela 05. Tempo de função versus Cargo - Escritórios Contábeis de Tangará da Serra/2012

\begin{tabular}{l|r|r|r}
\hline Tempo na função / Cargo & Auxiliar & Encarregada & Total Geral \\
\hline 1 ano e 10 meses & $3,57 \%$ & $0,00 \%$ & $3,57 \%$ \\
\hline 1 ano e 3 meses & $7,14 \%$ & $0,00 \%$ & $7,14 \%$ \\
\hline 1 ano e 5 meses & $7,14 \%$ & $0,00 \%$ & $7,14 \%$ \\
\hline 1 ano e 6 meses & $10,71 \%$ & $0,00 \%$ & $10,71 \%$ \\
\hline 1 ano e 8 meses & $3,57 \%$ & $0,00 \%$ & $3,57 \%$ \\
\hline 1 semana & $3,57 \%$ & $0,00 \%$ & $3,57 \%$ \\
\hline 10 anos & $3,57 \%$ & $0,00 \%$ & $3,57 \%$ \\
\hline 11 anos e 6 meses & $0,00 \%$ & $3,57 \%$ & $3,57 \%$ \\
\hline 18 anos e 4 meses & $3,57 \%$ & $0,00 \%$ & $3,57 \%$ \\
\hline 2 anos e 3 meses & $0,00 \%$ & $3,57 \%$ & $3,57 \%$ \\
\hline 2 anos e 6 meses & $7,14 \%$ & $0,00 \%$ & $7,14 \%$ \\
\hline 2 anos e 8 meses & $7,14 \%$ & $0,00 \%$ & $7,14 \%$ \\
\hline 3 anos & $3,57 \%$ & $0,00 \%$ & $3,57 \%$ \\
\hline 3 anos e 5 meses & $3,57 \%$ & $0,00 \%$ & $3,57 \%$ \\
\hline 4 meses & $14,29 \%$ & $0,00 \%$ & $14,29 \%$ \\
\hline 5 anos e 3 meses & $0,00 \%$ & $3,57 \%$ & $3,57 \%$ \\
\hline 5 meses & $3,57 \%$ & $0,00 \%$ & $3,57 \%$ \\
\hline 6 meses & $3,57 \%$ & $0,00 \%$ & $3,57 \%$ \\
\hline 7 meses & $3,57 \%$ & $0,00 \%$ & $3,57 \%$ \\
\hline Total Geral & $\mathbf{8 9 , 2 9 \%}$ & $\mathbf{1 0 , 7 1 \%}$ & $\mathbf{1 0 0 , 0 0 \%}$ \\
\hline F & & & \\
\hline
\end{tabular}

Fonte: Dados coletados pelo autor.

A participação masculina nos escritórios de contabilidade de Tangará da Serra tem se tornado cada vez mais escassa, diante do desenvolvimento e destaque que a mulher conquistou perante a sociedade. Algumas aptidões e qualidades tipicamente femininas 
A inserção da mulher como profissional contábil nos escritórios de contabilidade de Tangará da SerraMT

Ingrid Prudêncio Siqueira, Laércio Juarez Melz, Josiane Silva Costa dos Santos, Ariel Lopes Torres

ajudaram a tornar evidente a mulher no mercado de trabalho, tais como boa memória, organização, atenção aos detalhes e habilidade em desempenhar duas ou mais atividades simultaneamente.

Ponderando os questionamentos aplicados, observa-se a influência, eficácia e eficiência feminina. Diante do quadro de funcionários $17,86 \%$ dos cargos anteriormente exercidos por homens, atualmente são desempenhados por mulheres. Ainda que, haja promoções, demissões ou novas contratações, para estas novas oportunidades de vagas de emprego, nota-se a precisão da mulher em ocupá-las.

Tabela 05. Quem desempenhava a função anteriormente? - Escritórios Contábeis de Tangará da Serra/2012

\begin{tabular}{l|r}
\hline Cargo anterior exercido por: & \% \\
\hline Homem & $17,86 \%$ \\
\hline Mulher & $71,43 \%$ \\
\hline Não responderam & $10,71 \%$ \\
\hline Total Geral & $\mathbf{1 0 0 , 0 0 \%}$ \\
\hline
\end{tabular}

Fonte: Dados coletados pelo autor.

Como forma de reconhecimento das atividades desempenhadas, as organizações recompensam seus funcionários por meio de salários e até mesmo por bonificações, visando a satisfação e o bem estar, além de sela comprometimento com as partes envolvidas: empresa e empregado. Em alguns destes, o tratamento pode ser diferenciado, conforme o sexo do colaborador, proporcionando maiores regalias e benefícios em troca do aumento da qualidade do serviço prestado. Porém, em muitos casos, esta diferenciação ocorre apenas devido ao tempo de serviço e/ou graduação.

Como é possível notar na tabela 06, apenas uma minoria das entrevistadas, equivalente a pouco mais de $10 \%$, disseram não possuir salário equivalente ao de um homem na mesma função, porém estas possuem menor tempo na função ocupada que eles.

A faixa salarial, já foi alvo de grande preconceito se tratando das mulheres. Nos escritórios analisados, $28,57 \%$ das auxiliares de departamentos possuem remuneração entre R \$ 700,01 e R \$ 1.200,00. Por sua vez, estas estão cursando nível superior, e possuem o tempo mínimo de 4 meses na função e o máximo de 1 ano e 10 meses. As encarregadas, representantes de $10,71 \%$ do total de entrevistadas, exibem faixa salarial um pouco mais elevada, bem como o nível de instrução. Estas não somente concluíram nível superior, como também uma especialização, ou estão cursando uma pós graduação ou MBA.

Tabela 06. Equivalência Salarial ao homem na mesma função - Escritórios Contábeis de Tangará da Serra/2012 
A inserção da mulher como profissional contábil nos escritórios de contabilidade de Tangará da SerraMT

Ingrid Prudêncio Siqueira, Laércio Juarez Melz, Josiane Silva Costa dos Santos, Ariel Lopes Torres

\begin{tabular}{l|r}
\hline Equivalência salarial ao homem & \% \\
\hline Sim & $71,43 \%$ \\
\hline Não & $10,71 \%$ \\
\hline Não responderam & $17,86 \%$ \\
\hline Total Geral & $\mathbf{1 0 0 , 0 0 \%}$ \\
\hline
\end{tabular}

Fonte: Dados coletados pelo autor.

Tabela 07. Salário versus Cargo - Escritórios Contábeis de Tangará da Serra/2012

\begin{tabular}{l|r|r|r}
\hline Salário / Cargo & Auxiliar & Encarregada & Total Geral \\
\hline Até 700 & $14,29 \%$ & $00,00 \%$ & $14,29 \%$ \\
\hline R\$ 700,01 a R\$ 1.200,00 & $28,57 \%$ & $00,00 \%$ & $28,57 \%$ \\
\hline R\$ 1.200,01 a R\$ 1.700,00 & $25,00 \%$ & $07,14 \%$ & $32,14 \%$ \\
\hline R\$ 1.700,01 a R\$ 2.200,00 & $07,14 \%$ & $00,00 \%$ & $07,14 \%$ \\
\hline R\$ 2.000,01 a R \$2.700,00 & $03,57 \%$ & $00,00 \%$ & $03,57 \%$ \\
\hline R\$ 2.200,01 a R\$ 2.700,00 & $07,14 \%$ & $00,00 \%$ & $07,14 \%$ \\
\hline Acima de R\$ 2.700,01 & $00,00 \%$ & $03,57 \%$ & $03,57 \%$ \\
\hline Não responderam & $03,57 \%$ & $00,00 \%$ & $03,57 \%$ \\
\hline Total Geral & $\mathbf{8 9 , 2 9 \%}$ & $\mathbf{1 0 , 7 1 \%}$ & $\mathbf{1 0 0 , 0 0 \%}$ \\
\hline
\end{tabular}

Fonte: Dados coletados pelo autor.

\section{CONCLUSÃO}

Conforme coleta de dados, nota-se o grande desenvolvimento feminino na contabilidade. Mesmo com paradigmas a serem rompidas constantemente, as mulheres tem se sobressaído e ganhado destaque, buscando constantemente reconhecimento e valorização sobre o trabalho que realiza. Iniciando cada vez mais cedo na carreira contábil, as mulheres objetivam cargos e funções elevados pois acreditam em seu potencial.

Considerando o mercado de trabalho em um cenário nacional, tendo em vista a escassez da mão de obra qualificada, sabe-se que ter uma graduação é o indício de uma provável oportunidade de trabalho. Ao efetuar análise dos dados coletados e suas informações, é possível concluir que todas as mulheres presentes nos escritórios contábeis possuem nível de instrução, ainda que em processo de formação, de graduação.

Tendo em vista que quase $60 \%$ das mulheres entrevistadas ainda não concluíram nível superior, não podem assumir total responsabilidade de determinado setor, devido não possuírem total conhecimento sobre o mesmo. Com isso, estas fazem parte do quadro de auxiliares, seja fiscal, contábil ou recursos humanos. Aquelas que, concluíram nível superior, cursam ou finalizaram uma graduação, ocupam cargos de encarregadas. 
A inserção da mulher como profissional contábil nos escritórios de contabilidade de Tangará da Serra-

Ingrid Prudêncio Siqueira, Laércio Juarez Melz, Josiane Silva Costa dos Santos, Ariel Lopes Torres

Diante das dificuldades e preconceitos enfrentados diariamente, as mulheres arcam com responsabilidade a atividade que desempenham. As cobranças e muitas vezes a falta de credibilidade dos clientes e até mesmo dos próprios patrões, são estímulos para que elas busquem cada vez mais aprimoramento para uma boa desenvoltura profissional.

\section{REFERENCIAS}

ARANHA, Maria Lúcia de Arruda. História da educação. 2. ed. São Paulo: Moderna, 1996

ARARIPE, Tristão de Alencar. Código Civil Brasileiro. Rio de Janeiro: Laemmert, 1885.

ARAÚJO, Rafael Pereira Landim de. Disponível em <www.administradores.com.br >, 2008. Acesso em 18/03/2012

BELLO, José Luiz de Paiva. Metodologia cientifica . Rio de Janeiro: Pedagogia em foco, 2004. Disponível em: < http://www.pedagogiaemfoco.pro.br/ > Acesso em 15/03/2012

CARTES,Osmar. História do trabalho. Disponível em http://www.guatimozin.org.br> , 2006. Acesso em 18/03/2012.

CAUPERS, João. Os direitos fundamentais dos trabalhadores e a constituição. Coimbra: Almedina, 1985.

CERVO, Amado 1.; BERVIAN, Pedro A..Metodologia científica: para uso dos estudantes universitários. $3^{\text {a }}$ ed. São Paulo: McGraw-Hill do Brasil, 1983

CFC - Conselho Federal de Contabilidade. Disponível em <http://www.cfc.org.br/> Acesso em 25/03/2012

CFB - Constituição Federal Brasileira. Disponível em < http://www.planalto.gov.br/ > Acesso em 02/05/20012

DINIZ, Maria Helena. Curso de Direito Civil Brasileiro. 24 ed. São Paulo: FONSECA, Ozório José de Menezes; BARBOSA, Walmir de Albuquerque; MELO,Sandro Nahmias. Normas para elaboração de Monografias, Dissertações e Teses . Manaus: UEA, 2005. Disponível em: $<$ http://www2.uea.edu.br/ $>$ acesso em 30/04/2012

HAHNER, June E. Emancipação do sexo feminino. Florianópolis: Ed Mulheres, 2003.

IBGE - Instituto Brasileiro de Geografia e Estatística. Disponível em <http://www.ibge.gov.br/home/> acesso em 25/03/2012

IBOPE - Instituto Brasileiro de Opinião Pública e Estatística - 2004 - disponível em $<$ http://www.ibope.com.br/ > acesso em 01/05/2012

JULIANO, Rui. 2009. "Qual o Trabalho do Perito” disponível em < http://www.manualdepericias.com.br/ > acesso em 28/03/2012 
JÚLIO, Carlos Alberto. Reinventando você: a dinâmica dos profissionais e a nova organização. Rio de Janeiro: Campus, 2002.

KONDER, L. O que é dialética. São Paulo: Brasiliense, 1981.

LISBOA, Ibraim. 2010. "O que é a auditoria interna <http://www.portaldeauditoria.com.br/ $>$ acesso em 01/05/2012.

MARX, Karl. A ideologia alemã. In: Fernandes, F. Marx e Engels, Ed. Ática, 1983.

MARION, José Carlos, Contabilidade Básica. $7^{\circ}$ Ed, Editora Atlas, São Paulo.

NASCIMENTO, Cecília Vieira; OLIVEIRA, Bernardo J. O Sexo feminino em campanha a emancipação da mulher. Disponível em < http://www.scielo.br/>, 2006. Acesso em 20/03/2012.

OLIVEIRA, Silvio Luiz. Tratado de Metodologia Cientifica: Projetos de Pesquisa, TGI, TCC, Monografias, Dissertações e Teses. São Paulo: Pioneira Thomson Learning, 2002.

PARADA, Américo 2001. A importância da contabilidade. Disponível em < http://www.cosif.com.br/> Acesso em 02/05/2012

PARADA, Américo, 2009. Introdução a contabilidade. Disponível em < http://www.cosif.com.br/ > Acesso em 02/05/2012

POLONI, Antonio S. Pessoas e sociedades - conceitos e distinções,sd, disponível em <http://www.widesoft.com.br/>.Acesso em 02/05/2012

PROBST, Elisiana Renata. Evolução da mulher no mercado de trabalho. Disponível em Instituto Catarinense de Pós-Graduação < http://www.icpg.com.br $>2007$. Acesso em 23/03/2012.

REIS, Jair Teixeira dos. Relação de trabalho: estagio de estudantes. Ed. Juruá, 2006. Saraiva, 2007

SILVA, Edna Lúcia da; MENEZES, Estera Muszkat. Metodologia da pesquisa e elaboração de dissertação . $3^{\mathrm{a}}$ ed. rev. atual. - Florianópolis: Laboratório de Ensino a Distância da Universidade Federal de Santa Catarina - UFSC, 2001. Disponível em: < http://projetos.inf.ufsc.br/ > acesso em 30/04/2012 